Journal of the East Africa and Uganda Natural History Society. March, 1917. Longmans, Green, and Co. Price 5s. $4 d$. - The relation of climate to health gives particular interest to the several articles which have appeared from time to time in this journal on desiccation or the gradual drying up of rivers and lakes in Africa. In the current issue Mr. R. L. Harger gives a summary of observations on the subject made by older travellers-namely, Mr. G. W. Stow (oiroa 1843) and Livingstone-and records his own observations made between the years 1894 and 1906. A review of the facts stated show that the inland plateau of Africa up to the Equator can be divided roughly into three lateral zones (1) From about the latitude of the Orange River to the Zambesi, where vast rivers and lakes have disappeared, leaving mere remnants, such as Lake Ngami ; (2) from the Zambesi to the latitude of Lake Mweru, where large river systems and huge lake areas are in process of being drained; and (3) the equatorial belt, excluding Tanganyika, where the climate, rainfall, and vegetation are such, together with abundance of water, as to warrant the supposition that drainage and desiccation have not yet commenced. - A short note on Albinism in East Africa, by Mr. S. L. Hinde, expresses the opinion that possibly a larger percentage of albinos are born to negro parents in tropical Africa than is born to European parents in Europe. These children are seldom seen by Europeans, as many tribes destroy them at, or soon after, birth, and those that are allowed to survive are difficult to rear. Under the title of "A Rare Forest Francolin," Dr. V. G. L. van Someren, the honorary secretary of the society, describes the Francolinus lathami sohubotzi, and a beautiful coloured plate shows the male and female of these birds.

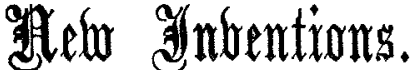

\section{A BED-CARRIER.}

AT this hospital last summer on fine days patients were carried out of doors in their beds. This necessitated carrying the bed and patient 100 yards and up and down a broad flight of ten steps. Four strong men were required to carry a single bed, and for four men it was a considerable exertion. From unequal lifting it was a strain on the bedstead. The bedsteads are light, of the ordinary hospital pattern, measuring $6 \mathrm{ft} .4 \mathrm{in}$. by $3 \mathrm{ft} .3 \mathrm{in}$.

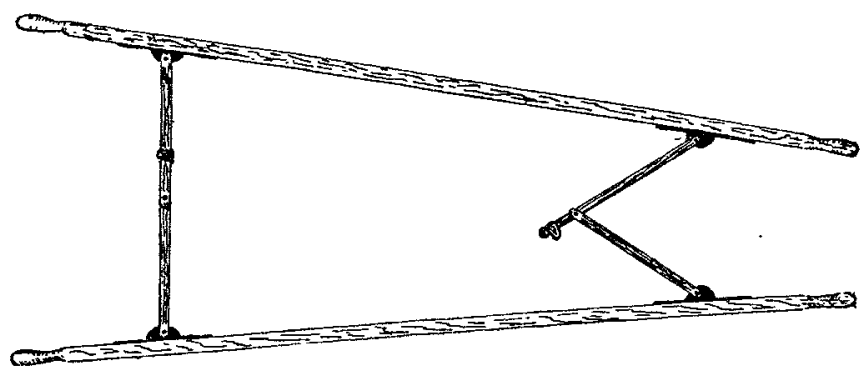

The hospital carpenter made a bed-carrier by the use of which two men could do the work of four with less exertion. It is a simple contrivance. No claim is made for originality, but in view of its convenience its description is made known.

It corsists of two stretcher poles, each measuring $104 \times 1 \frac{1}{4} \times 2 \frac{1}{2}$ inches, their ends fashioned to form handles (see figure). The poles are joined at a distance from either end, corresponding with the head and foot of the bed, by a jointed flat iron bar, one-half of which overlaps the other at the central join. The longer half is turned over at its end to grip its fellow, thus preventing over-extension. Fach half has a hinged attachment to the pole to allow of the two poles being collapsed together. The carrier in use, when the jointed bars are extended, lies under the bed frame. Four buttresses on the poles rest hard up against each leg of the bedstead to prevent the bed slipping when carried up an incline. The two jointed bars when fully extended form a rigid iron bar which prevents collapse of the poles when a man at each end lifts the pole handles to carry.

R.N. Hospital, Mount Stuart.

A. Geoffrey Evans, Temporary Surgeon, R.N.
WRIST- AND FOOT-DROP SPLINTS.

THE following is a description of two splints which have been found very useful in the prevention and treatment of " wrist-drop" and "foot-drop "in cases of injury to muscle and nerve. They have been designed by Miss Wharton, one of the dressers in the Hôpital Temporaire d'Arc-en-Barrois (Haute-Marne).

The splint is made of iron wire, strong enough to support the limb but capable of forcible bending to fit it to the peculiarities of individual cases. It consists, as will be seen in the illustrations, of a support on the palmar or plantar aspect of the limb, attached to a wire, which, passing between the index and middle fingers or great and second toe, crosses the dorsal surface of the hand or foot without
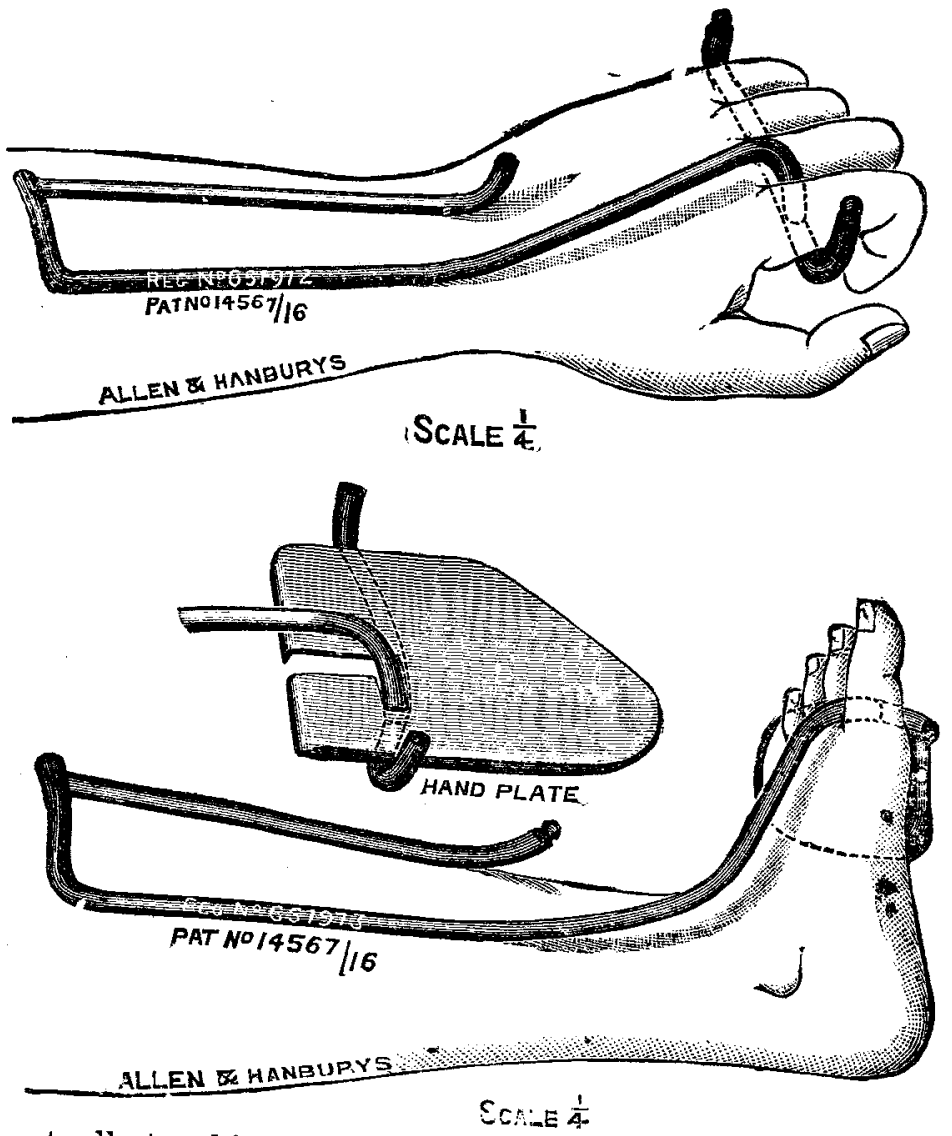

actually touching it, and continuing up the forearm or leg is fixed in the manner shown in the drawing, by a few turns of bandage. In the foot-splint the support is made in sheet metal, while in the hand it consists only of a single wire with a detachable sheet-metal finger support. In "foot-drop" the advantages of the splint as compared with the ordinary back splint, for example, are: Its simplicity, lightness (the patient is perfectly free to adopt any change of position he cares to without suffering the restraining influence of the heavy posterior splint), ease of appliance-e.g., a few turns of a bandage on the leg only, which renders it capable of appliance in spite of wounds, adaptability to cases, absence of any risk of pressure sore in the heel region and possibility of walking on crutches while wearing the splint. In " wristdrop" its light weight is again the most commendable attribute, and the fact that the splint is fixed by a bandage on the forearm only, leaving the hand free and enabling the fingers to be used while the wrist is supported in a position of dorsiflexion to the amount desired for the case. If it is thought desirable to keep the fingers in an extended position the detachable finger support is used. If it were objected that there were pressure on the affected muscles, which is almost inconceivable in such a light apparatus, a modified form in which the arm-piece is applied to the anterior surface of the forearm is made. These splints are in constant use in the Arc-en-Barrois Hospital and have been found very effective in the prevention and treatment of foot- and wrist-drop and after nerve sutures. They have also been commended and adopted by certain French surgeons of other hospitals.

The splints are made and supplied by Messrs. Allen and Hanburys, Limited, 48, Wigmore-street, London, W., and catalogued by them as the "Wharton's Splint."

\section{A. F. SINCLAIR,}

Gurgeon, Hôpital Temporaire, Arc-en-Barrois 